Journal of Animal and Veterinary Advances 11 (12): 2059-2063, 2012

ISSN: $1680-5593$

(C) Medwell Journals, 2012

\title{
Identification of Genetic Variants Within Androgen Receptor Gene of Sika Deer and its Association with Antler Production
}

\author{
Jiajun Xiong, Feifei Yang, Guohua Hua, Lei Shen, Bin Fan, Pu Zhang, \\ Lijun Huo, Shujun Zhang and Liguo Yang \\ Key Laboratory of Agricultural Animal Genetics Breeding and Reproduction, \\ Ministry of Education, College of Animal Science and Technology, \\ Huazhong Agricultural University, 430070 Wuhan, P.R. China
}

\begin{abstract}
Antler production is one of the most important economical traits of Sika deer. However, the genetic mechanism of antler growth and genetic markers associated with antler yield remain unclear. In the present study Androgen Receptor $(A R)$ gene has been considered as a candidate gene to identify the polymorphisms. Besides, its effect on antler production was investigated in Chinese Sika deer. Genomic sequences of exons 1-7 of Sika deer have been successfully obtained and showed high homogeneity with bovine. One SNP ss 325995755 was identified in exons3. Genotyping of SNP and association analyses with antler yield were analyzed in two Chinese Sika deer populations $(n=215)$. The SNP ss325995755 was not significantly $(p>0.05)$ associated with average antler yield.
\end{abstract}

Key words: Androgen receptor gene, antler growth, association, Sika deer, significantly

\section{INTRODUCTION}

Sika deer is classified into Mammalia, Artiodactyla, Cervidae, Cervu. The ancestries of Cervidae species were earliest originated at Oligocene of the Tertiary Period and Sika deer was mostly possibly derived from North China at the late of Pliocene Epoch which was $>3$ million years ago (Corbet and Hill, 1991). China is one of the three largest productive countries in the world and has a long deer breeding history which could date back from Shang Dynasty in 11BC (Dong et al., 2000). Domestic deer industry has developed rapidly and till now there are more than thousands of deer farms in China. The total number of Sika deer is $>300$ thousands.

Antler is the most important products of deer farming and has great economic values because it is one of the precious Chinese medicines and has various kinds of medical and health care roles. Antler is one of the fastest growing parts of deer body. It has round end, fuzzy coat and full of connective tissue and cartilaginous tissue inside. The previous researches have demonstrated that antler size was associated an individual's nutritional state (Kruuk et al., 2002). Antler production was significantly related to the deer's live weight (Zeng et al., 2002). Besides, antler formation and growth rate are also, related to sex hormones including progesterone, thyroid hormone, adrenocortical hormone, chorionic gona-dotropin (Sempere and Lacroix, 1982; Li, 2003; Gao, 1999; Bartos etal., 2009; Bubenik et al., 1987, 1997).

Androgen is important for male reproductive organ development and function maintenance of humans and animals. Androgen Receptor (AR) is one of type I steroid receptors and is a ligand-dependent transregulator protein. Androgen concentrations were low and antler growth had commenced and was proceeding rapidly in the velvet from March through July (Mirarchi et al., 1977). The antler cycle of Southern pudu is very sensitive to manipulation of androgen levels (Bubenik et al., 2002). Recently, a few of molecular studies and association analyzes between antler growing trait and candidate genes such as Growth Hormone (GH) and Major Histocompatibility Complex (MHC) have been carried out (Swarbrick et al., 1995; Du and Bai, 2004). Results showed an effect of $G H$ gene on antler production. Deer with the SNP genotypes $\mathrm{G} \rightarrow \mathrm{A}$ had a significant difference in antler production of the fifth saw ( $<<0.2)$ (Du and Bai, 2007). Nine alleles of the second exon of MHC-DRB gene that are significantly positively correlated to the antler produetivity were diseovered ( $\mathrm{Li}, 2003)$. These results showed that screening more candidate genes related to antler growing is very important. In this study, $A R$ gene

Corresponding Author: Liguo Yang, Key Laboratory of Agricultural Animal Genetics Breeding and Reproduction, Ministry of Education, College of Animal Science and Technology, Huazhong Agricultural University, 430070 Wuhan, P.R. China 
was considered as one of candidate genes and the association between $\mathrm{AR}$ genotypes and antler growth traits were explored so as to find the potential molecular markers related to antler growing which can be used for Marker Assisted Selection (MAS) programs in Sika deer industry.

\section{MATERIALS AND METHODS}

Animals: All procedures involving animals were approved by the Animal Care and Use Committee of Huazhong Agricultural University. A total of 215 Sika deers were examined in this study which were obtained from 2 deer farms including Wusan Sika deer farm ( $\mathrm{n}=136$, Jingmen city, Hubei Province), Dongfeng county Sika deer farm ( $\mathrm{n}=79$, Jilin province). Approximate $10 \mathrm{~mL}$ blood per Sika deer was collected, aseptically from the jugular vein and kept in a tube containing anticoagulant EDTA (Ethylenediaminetetraacetic acid). All samples were delivered back to the laboratory in an ice box. The genomic DNA was extracted from white blood cells using standard phenol-chloroform extraction protocol (Joseph and David, 2002). The DNA samples were dissolved in TE buffer which was made from $10 \mathrm{mM}$ Tris- $\mathrm{Cl}(\mathrm{pH} 7.5)$ and $1 \mathrm{mM}$ EDT A $(\mathrm{pH} 8.0)$ and were stored at $-20^{\circ} \mathrm{C}$ for use. The animals from Shuangyang Sika deer and Dongfeng Sika deer had the detailed records of antler harvest time and fresh weight.

Mutation detecting and genotyping: A total of 8 pairs of primers were designed using Primer 5.0 (PREMIER Biosoft Inc, Palo Alto, CA, USA) on the basis of DNA sequence of the bovine AR (Accession: NC007331, Z75313, Z75314, Z75315) (Table 1). The primers were synthesized by Sangon Biotech Company (Shanghai, China). Both PCR

Table 1: The primer sequence for Sika deer $A R$ gene

\begin{tabular}{lccc} 
Primer sequence $\left(5^{\prime} \rightarrow 3^{\prime}\right)$ & $\begin{array}{c}\text { Annealing } \\
\text { temp. }\left({ }^{\circ} \mathrm{C}\right)\end{array}$ & $\begin{array}{c}\text { Product } \\
\text { size }(\mathrm{bp})\end{array}$ & $\begin{array}{c}\text { Region } \\
\text { amplified }\end{array}$ \\
\hline $\begin{array}{l}\text { TTCAGAGTGTATGCGAAGTGA } \\
\text { ATGTTGGAAGGCTGCTGT }\end{array}$ & 57.0 & 218 & exon1 * \\
$\begin{array}{l}\text { CCCTGGAAGAGGAACAGCA } \\
\text { TGTCTTTAAGATCGGTGGAGC }\end{array}$ & 52.2 & 225 & exon1** \\
$\begin{array}{l}\text { ATTATTCCTCTTGGGTCT } \\
\text { ACTGCCAGTGACTTTGTC }\end{array}$ & 56.5 & 284 & exon2 \\
$\begin{array}{l}\text { TTAACAGGGCTGTCTACT } \\
\text { GTATCATACCTCCCAGAG }\end{array}$ & 54.1 & 163 & exon3 \\
$\begin{array}{l}\text { TAAATCCAACTTTCCTTCT } \\
\text { GCTGACACTCATAGCCTTC }\end{array}$ & 58.5 & 159 & exon4 \\
$\begin{array}{l}\text { CAGTCTGACCATTGCCTGTG } \\
\text { CCGTTATCGCCATGAACC }\end{array}$ & 51.5 & 236 & exon5 \\
$\begin{array}{l}\text { TACCCCTCTCTTTTCTCTGTGTGTT } \\
\text { CCCTTCCAGGCACTTACT }\end{array}$ & 57.6 & 183 & exon6 \\
$\begin{array}{l}\text { CCCCATTCTGTCTTCATC } \\
\text { ACCCTCCATTGTTTGCTT }\end{array}$ & 57.1 & 205 & exon7 \\
\hline
\end{tabular}

*Indicates one primer of exon1; **Indicates another primer of exon1 reactions were performed in a $10 \mu \mathrm{L}$ mixture containing $1 \times$ PCR buffer, $0.2 \mathrm{uM}$ each primer, $150 \mathrm{uM}$ each $\mathbb{d N T P}$, $1.5 \mathrm{mM} \mathrm{MgCl}_{2}, 2 \mathrm{U}$ Taq DNA polymerase (Takara Company, Dalian, China) and 12.5 ng genomic DNA. PCR reactions were comprised of the initial denaturation at $95^{\circ} \mathrm{C}$ for $5 \mathrm{~min}, 30$ cycles with $94^{\circ} \mathrm{C}$ for $30 \mathrm{sec}, 62^{\circ} \mathrm{C}$ for $30 \mathrm{sec}, 72^{\circ} \mathrm{C}$ for $30 \mathrm{sec}$ followed by a final extension at $72^{\circ} \mathrm{C}$ for $5 \mathrm{~min}$. These sequences were then blast with bovine $A R$ gene sequence to obtain the homology between species. PCR-SSCP Method was used to detect the polymorphisms. Two-direction sequencing of the amplicons was implemented by BGI Ark Biotechnology Company (Shenzhen, China) to detect the mutations.

Data statistics: The association analyses were implemented using GLM Model procedure (SAS 9.0; SAS Institute, Cary, NC, USA). The model was showed as follows:

Where:

$$
\mathrm{P}_{\mathrm{ijk}}=\mu+\mathrm{G}_{\mathrm{i}}+\mathrm{Q}_{\mathrm{ik}}+\mathrm{e}_{\mathrm{ijk}}
$$

$\mathrm{P}_{\mathrm{ijk}}=$ The different saw antler harvest capability of animal

$\mu=$ The population mean

$\mathrm{G}_{\mathrm{i}}=$ The fixed effect of genotype

$\mathrm{Q}_{\mathrm{ik}}=$ The fixed effect of different farm

$\mathrm{e}_{\mathrm{ijks}}=$ The random residual error

\section{RESULTS AND DISCUSSION}

Genotypes and diversities: About 8 pairs of primers of the $A R$ gene were amplified from sika deer genomic DNA as expected (Fig. 1). PCR-SSCP method was used to detect the polymorphism of $A R$ gene exonl-7 (Fig. 2). These results showed that there was no genetic variation in exon1-7 while 1 mutation was identified in exon3 (T75C). The mutation was submitted to the GeneBank and acquired the dbSNP Accession No.: ss325995755 and then the exon3 sequence was submitted to Genebank (Accession: JF719040). The transition of T75C caused an amino acid change from Val to Ala. However, The SNP destroyed the restriction site recognized by endonuclease Rsal. These following DNA restriction fragments were generated by the AR-Rsa/polymorphisms: 88,49 and $26 \mathrm{bp}$ for CC genotype, 114 and $49 \mathrm{bp}$ for TT genotype, 114, 88, 49 and 26 bp for CT genotype (Fig. 3). At T75C locus, 194 deers were homozygous (CC), 5 deers were heterozygous (CT) and 16 deers were homozygous (TT) (Table 2). In the tested Sika deer population, 3 kinds of genotypes were found in Dongfeng Sika deer populations. Nevertheless, only $\mathrm{CC}$ and TT homozygote genotype were observed in Wusan Sika deer populations. Allele $\mathrm{C}$ was predominant in all of populations. 


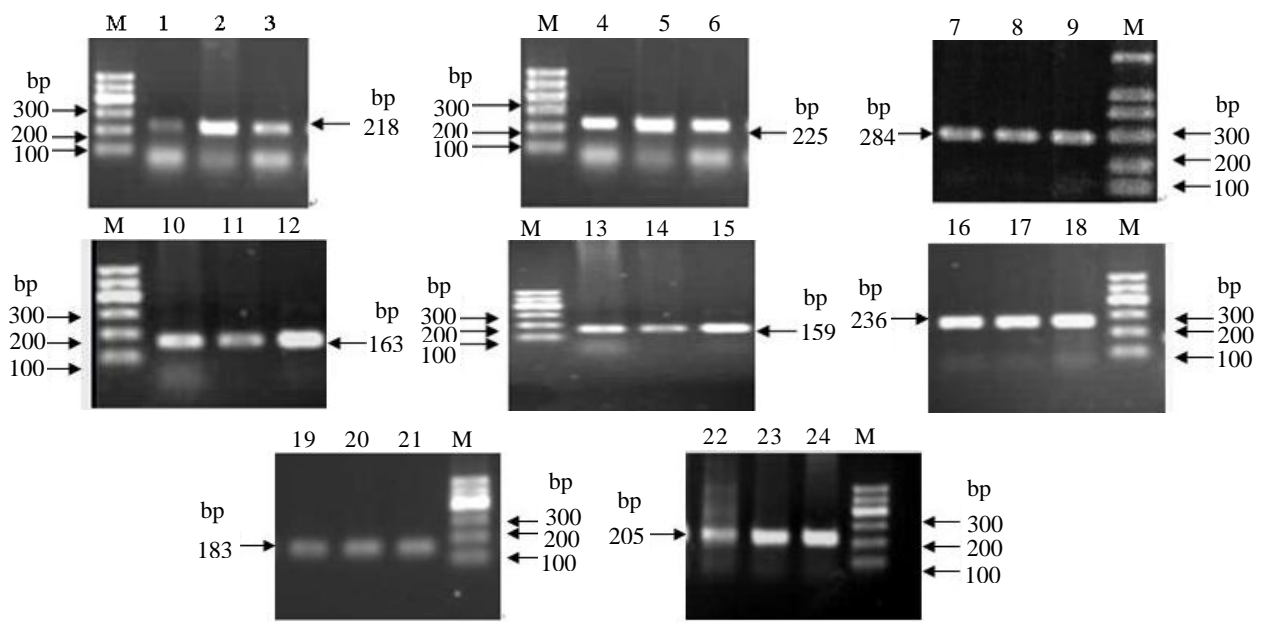

Fig. 1: Electropherotic profile for the AR fragments amplified by PCR in a $1.2 \%(\mathrm{w} / \mathrm{v}(5 \mathrm{~V} / \mathrm{cm})$ agarose gel. A stand with 218 bp (Lanes 1-3), 225 bp (Lanes 4-6), 284 bp (Lanes 7-9), 163 bp (Lanes 10-12), 159 bp (Lanes 13-15), 236 bp (Lanes 16-18), 183 bp (Lanes 19-20) and 205 bp (Lanes 22-24) appeared to represent amplicons using primer exonl*, exon1 ${ }^{* *}$, exon2-7, respectively. M represented a Marker I (600, 500, 400, 300, 200 and $\left.100 \mathrm{bp}\right)$

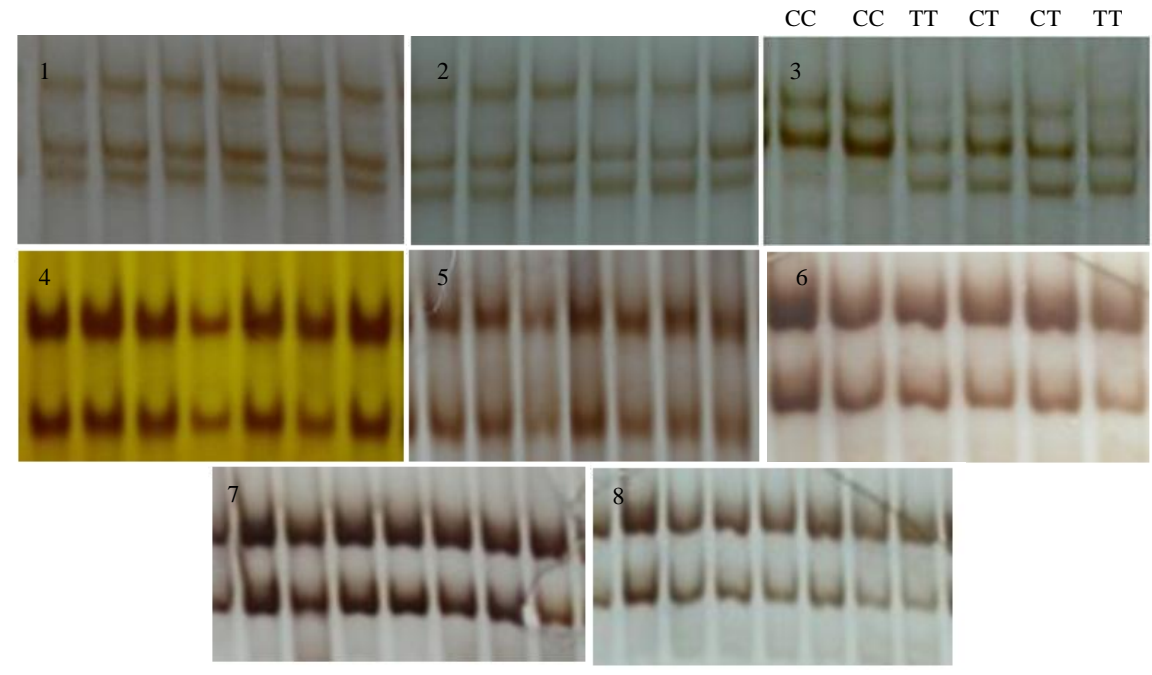

Fig. 2: PCR-SSCP for the genotype of $A R$ gene exon1 -7, 1-8 represent primer exonl ${ }^{*}$, exonl ${ }^{* *}$, exon2-7, respectively

Table 2: The genotypic and allelic frequencies of the androgen receptor gene in Sika deer

\begin{tabular}{lcc}
\hline Genotype & Genotype frequency & Allele frequency \\
\hline CC (194) & 0.90 & C 0.92 \\
CT (5) & 0.03 & T 0.08 \\
TT (16) & 0.07 & - \\
\hline
\end{tabular}

Association of genotypes with antler yield traits: Association analyze showed that there was no significant differences between antler yield and the genotypes $(p>0.05)$ at saw 1-5 (Table 3). However, there was a tendency that CT genotype individuals had worse performance in yield traits than $\mathrm{CC}$ and TT genotype. The biological procedure of antler formation, growth and regeneration of Sika deer is complicated and there is little known about the molecular mechanism regulating this procedure. At present, most of molecular studies are on association between antler growing trait and candidate genes such as Growth Hormone (GH) and Major Histocompatibility Complex (MHC). In this study, exons sequencing, genotyping and association of Sika deer $A R$ gene were implemented. It was found that a nonsynonymous mutation in exon3. Association analyses showed that there was no significantly association between average antler yield and genotypes $(p>0.05)$. However, CT genotype individuals were lower in yield traits than $\mathrm{CC}$ and TT individuals from the 1st saw to the 
Table 3: The association of genotypes with antler yield of different saw in Sika deer Antler y ield $(\mathrm{g}) \pm \mathrm{SD}$

\begin{tabular}{|c|c|c|c|c|c|}
\hline \multirow[b]{2}{*}{ Genoytpe } & & & & & \\
\hline & Saw 1 & Saw 2 & Saw 3 & Saw 4 & Saw 5 \\
\hline$\overline{\mathrm{CC}(194)}$ & $519.82 \pm 61.55$ & $1098.27 \pm 96.87$ & $1753.99 \pm 86.89$ & $1910.27 \pm 65.74$ & $2392.84 \pm 91.80$ \\
\hline CT (5) & $402.84 \pm 166.45$ & $724.59 \pm 376.66$ & $1440.91 \pm 432.74$ & $1334.15 \pm 359.14$ & $1909.84 \pm 745.25$ \\
\hline TT (16) & $400.95 \pm 157.28$ & $1082.50 \pm 316.10$ & $1861.46 \pm 304.34$ & $1963.18 \pm 229.35$ & $2469.54 \pm 277.13$ \\
\hline
\end{tabular}

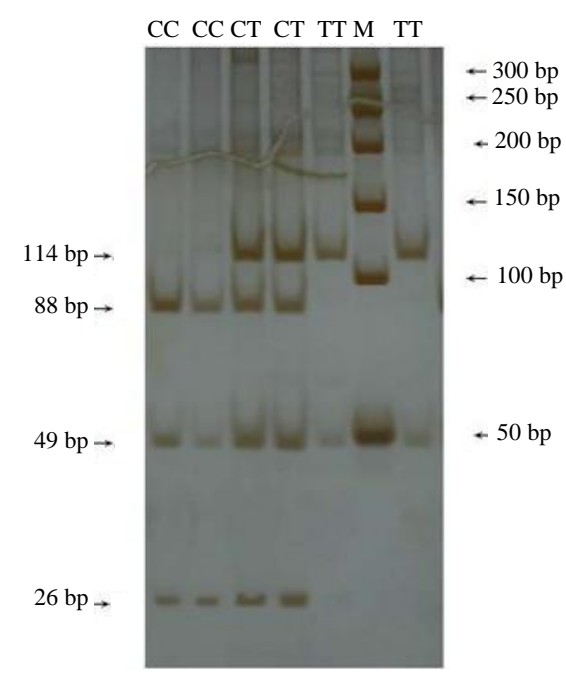

Fig. 3: Representative genotyping of $A R$ gene at locus $\mathrm{T} 75 \mathrm{C}$ by polyacrylamide gel electrophoresis. Stands with 88, 49 and 26 bp for CC genotype, 114 and $49 \mathrm{bp}$ for TT genotype, 114, 88, 49 and $26 \mathrm{bp}$ for CT genotype appeared at this locus. $M$ represented a market with 50 bp DNA Ladder/RSA I $(500,400,300,250,200,150,100$ and $50 \mathrm{bp}$ )

5 th saw. It was consistent with the genotype frequency that CT was the lowest. It suggested that this locus was possibly associated with the major gene regulating the antler yield. The CT individuals may be eliminated by artificial selection as the poor performance. In the previous studies in Finnish men at the beginning of the CAG repeat in the exonl of the androgen receptor gene the 173A--> T (Q58L) substitution might be the cause of infertility (Lund et al., 2003) in human, exon7 of the androgen receptor gene, Gln824Lys mutation in the ligand-binding domain of to cause slight impairment of receptor function but was compatible with preservation of male fertility (Giwercman et al., 2000).

In this study, 2 pairs of primers was designed based on exonl sequence, no genetic variant was identified. The possible reasons are relatively small sample size of the analyzed population and alleles have been fixed due to long term artificial selection. This study also implied that $A R$ gene may involve in the growth and development of antler of Sika deer. In the future research, SNP detection could be implemented in other un-detected coding region and introns. Additionally, enlarged populations with different genetic background are also warranted.

\section{CONCLUSION}

In the present study, genomic sequences of seven exons of Sika deer were obtained using comparative homologous amplification. SNP from exon3 of androgen receptor of Sike deer including a non-synonymous mutation GTA (Val)/GCA (Ala) were identified in Chinese Sika deer population. PCR-RsaI-RFLP was developed for genotyping in two Sika deer populations. The result showed that there was no significantly $(p>0.05)$ association with the antler yield. However, there was a tendency that CT genotype individuals had worse performance in yield traits than CC and TT genotype. Therefore, the $A R$ gene could be considered as a candidate gene for antler production of Sika deer. Besides, additional causative mutation discovery and association implication are warranted.

\section{ACKNOWLEDGEMENTS}

Researchers thank Jingmen City Wusan Sika deer Farm in Hubei province, Dongfeng County Sika deer Farm and Jilin city Longtanshan Sika deer Farm in Jilin province for their assistance on blood sample and data collection. This study was supported by both the Fundamental Research Funds for the Central Universities (2010PY013) and the province Natural Science Foundation of Hubei (2010CDB10108). Jiajun Xiong and Feifei Yang contributed equally to this research.

\section{REFERENCES}

Bartos, L., D. Schams, G.A. Bubenik, 2009. Testosterone but not IGF-1, LH, prolactin or cortisol, may serve as antler-stimulating hormone in red deer stags (Cervus elaphus). Bone, 44: 691-698.

Bubenik, G.A., A.J. Sempere and J. Hamr, 1987. Developing antler, a model for endocrine regulation of bone growth. Concentration gradient of T3, T4 and alkaline phosphatase in the antler, jugular and the saphenous veins. Calcified Tissue Int., 41: 38-43. 
Bubenik, G.A., D. Schams, R.J. White, J. Rowell, J. Blake and L. Bartos, 1997. Seasonal levels of reproductive hormones and their relationship to the antler cycle of male and female reindeer (Rangifer tarandus). Comp. Biochem. Phys. B., 116: 269-277.

Bubenik, G.A., E. Reyes, D. Schams, A. Lobos, L. Bartos and F. Koerner, 2002. Effect of antiandrogen cyproterone acetate on the development of the antler cycle in Southern pudu (Pudu puda). J. Exp. Zool., 292: 393-401.

Corbet, G.B. and J.E. Hill, 1991. A World List of Mammalian Species. 3rd Edn., Oxford University Press, USA., ISBN-10: 0198540175.

Dong, W.C., X.L. Zhang, C.H. Liu, B.X. Zhang, L.B. Zhao and Y. Tian, 2000. Sudies on stracture and biological effect of sika velvetantler poplypeptide. Spec. Wild Econ. Anim. Plant Res., 22: 7-10.

Du, Z.H. and X.J. Bai, 2004. Cloning and sequencing analysis of GH-I gene in sika deer. J. Econ. Anim., 8: 131-134.

Du, Z.H. and X.J. Bai, 2007. Association analysis between SNPs of the growth hormone gene and antler production in spotted deer. Hereditas, 29: 337-342.

Gao, Z.G., 1999. Study on the relationship between growth speed of antler and the contents of testorone and estradiol in sika deer. J. Econ. Anim., 3: 27-30.

Giwercman, A., T. Kledal, M. Schwartz, Y.L. Giwercman and H. Leffers et al., 2000. Preserved male fertility despite decreased androgen sensitivity caused by a mutation in the ligand-binding domain of the androgen receptor gene. J. Clin. Endocrinol. Metab., 85: 2253-2259.
Joseph, S. and W.R. David, 2002. Molecular Cloning: A Laboratory Manual. 3rd Edn., Cold Spring Harbor, USA., pp: 483-485.

Kruuk, E.B., J. Slate, J.M. Pemberton, S. Brotherstone, F. Guinness and T. Clutton-Brock, 2002. Antler size in red deer: Heritability and selection but no evolution. Evolution, 56: 1683-1695.

Li, B., 2003. A Study on the Polymorphism of MHC-DRB Genes and Their Relatedness to the Antler Productivity in Sika Deer (Cervus nippon). Northeast Forestry University.

Lund, A., V. Juvonen, J. Lahdetie, K. Aittomaki, J.S. Tapanainen and M.L. Savontaus, 2003. A novel sequence variation in the transactivation regulating domain of the androgen receptor in two infertile Finnish men. Fertil Steril., 79: 1647-1648.

Mirarchi, R.E., P.F. Scanlon, R.L. Kirkpatrick and C.B. Schreck, 1977. Androgen levels and antler development in captive and wild white-tailed deer. J. Wild Manage., 41: 178-183.

Sempere, A.J. and A. Lacroix, 1982. Temporal and seasonal relationships between $\mathrm{LH}$, testosterone and antlers in fawn and adult male roe deer (Capreolus capreolus) a longitudinal study from birth to 4 years age. Acta Endocrinol., 99: 295-301.

Swarbrick, P.A., F.W. Schwaiger, J.T. Epplen, G.S. Buchan, J.F.T. Griffin and A.M. Crawford, 1995. Cloning and sequencing of expressed DRB genes of the red deer (Cervus elaphus) Mhc. Immunogenetics, 42: 1-9.

Zeng Z.H., S.H., B. Chen, Sh.L. Yang and Z.H. Zhou, 2002. Analysis of antler producing performance in the Northeast Sika Deer. J. Econ. Anim., 6: 23-25. 